Research Paper

\title{
Polydatin Increases Radiosensitivity by Inducing Apoptosis of Stem Cells in Colorectal Cancer
}

\author{
Qiu Chen ${ }^{1,2^{*}}$, Ya-Nan Zeng $3^{3 *}$, Ke Zhang, ${ }^{2}$, Ying Zhao ${ }^{1,2}$, Yong-You Wu ${ }^{4}$, Gen Li², Hui-Ying Cheng ${ }^{2}$, Meng \\ Zhang ${ }^{1,2}$, Feng Lai ${ }^{1,2}$, Jin-Bing Wang ${ }^{5 凶}$, Feng-Mei Cui ${ }^{1,2}{ }^{\circledR}$ \\ 1. State Key Laboratory of Radiation Medicine and Protection, School of Radiation Medicine and Protection, Soochow University, Suzhou 215123, P R China \\ 2. Collaborative Innovation Center of Radiation Medicine of Jiangsu Higher Education Institutions, Suzhou 215123, P R China \\ 3. Department of Occupational Health, Wuxi Center for Disease Control and Prevention, Wuxi 214023, P R China \\ 4. Department of Surgery, the Second Affiliated Hospital of Soochow University, Suzhou 215000, P R China \\ 5. Department of Oral and Maxillofacial-Head and Neck Oncology, Shanghai Ninth People's Hospital, College of Stomatology, Shanghai Jiao Tong University \\ School of Medicine; Shanghai Key Laboratory of Stomatology \& Shanghai Research Institute of Stomatology; National Clinical Center for Oral Disease, \\ Shanghai 200011, P R China.
}

"These authors have contributed equally to this work.

$\triangle$ Corresponding authors: Feng-Mei Cui, Department of Radiation Medicine, School of Radiation Medicine and Protection, Medical College of Soochow University, Suzhou 215123, China; Email: cuifengmei@suda.edu.cn. Jin-Bing Wang, Department of Oral and Maxillofacial-Head and Neck Oncology, Shanghai Ninth People's Hospital, College of Stomatology, Shanghai Jiao Tong University School of Medicine; Shanghai Key Laboratory of Stomatology \& Shanghai Research Institute of Stomatology; National Clinical Center for Oral Disease, Shanghai 200011, P R China. E-mail: wangjinbing@aliyun.com.

(C) Ivyspring International Publisher. This is an open access article distributed under the terms of the Creative Commons Attribution (CC BY-NC) license (https://creativecommons.org/licenses/by-nc/4.0/). See http://ivyspring.com/terms for full terms and conditions.

Received: 2018.05.03; Accepted: 2018.12.07; Published: 2019.01.01

\begin{abstract}
This study aimed to investigate the radiosensitizing effect of polydatin (PD) on colorectal cancer (CRC) and its underlying mechanism. The C57BL/6 mouse model of CRC was induced by treatment with azoxymethane (AOM)/dextran sodium sulfate (DSS) and then divided into four groups: control, PD alone, IR alone, and combination of PD and IR. Radiation therapy (200 cGy/min, 10Gy) was performed in mice in the experimental groups for once a week with a total of four times. Thirty minutes before IR, mice were intraperitoneally injected with PD at the dose of $25 \mathrm{mg} / \mathrm{kg}$. The number and volume of CRC xenografts were calculated. Immunohistochemical staining was performed to detect the expression of $\mathrm{Ki} 67$ and cleaved caspase- 3 in tumor tissues samples. The effects of PD on proliferation and apoptosis were evaluated in CT26 and HCT1 16 colon tumor cells. Leucine-rich repeat-containing G-protein coupled receptor 5 positive $\left(\mathrm{Lgr}^{+}\right)$cancer stem cells (CSCs) were sorted from CT26 cells and the effects of PD on their proliferation and apoptosis were observed to elucidate the radiosensitizing mechanism of PD in CRC cells. Combined therapy with PD and IR significantly decreased tumor volume, inhibited proliferation and induced apoptosis of tumor cells in the mouse model of CRC compared to other three groups. Compared to the IR group, in vitro assay showed that PD combined with IR inhibited proliferation and promoted apoptosis of $\mathrm{CT} 26$ and $\mathrm{HCT} 116$ colon tumor cells as well as $\mathrm{Lgr5}^{+} \mathrm{CSC}$. However, addition of the bone morphogenetic protein (BMP) type I receptor inhibitor K02288 $(6.4 \mathrm{nM})$ dramatically increased proliferation of $\mathrm{Lgr}^{+} \mathrm{CSC}$ s and abolished the cytotoxic effect of PD combined with IR on $\mathrm{Lgr5}{ }^{+} \mathrm{CSC}$. The in vivo and in vitro experiments demonstrated that IR combined treatment with PD could inhibit proliferation and promote apoptosis of CRC cells and $\mathrm{Lgr} 5^{+} \mathrm{CSCs}$, and BMP signaling pathway was involved in the radiosensitizing effect of PD.
\end{abstract}

Key words: Polydatin, radiosensitivity, Lgr5 ${ }^{+}$cancer stem cells, colorectal cancer

\section{Introduction}

Colorectal cancer (CRC) is the third most common cancer in the world and is the fourth leading cause of cancer-related death [1]. Chemoradiotherapy is regarded as a standard treatment for locally advanced CRC, especially, middle and distal rectal cancers. However, advances in many 
chemoradiotherapy methods of CRC are limited by the development of chemoradiation resistance (CRR) [2-3]. Hence, finding a good radiosensitizer and clarifying its molecular mechanism is essential in CRC.

Recent studies have shown that cancer stem cells (CSCs) have greater radiation resistance and chemotherapy tolerance, determining the tumor fate and the efficacy of radio/chemotherapy [4-5]. It has been reported that non-small cell lung cancer cells survived ionizing radiation treatment display complex phenotypes, including CSCs and epithelial-mesenchymal transition features [6]. Another study has found that $\mathrm{CD}_{133^{+}}$liver cancer stem cells exhibit a higher self-renewal capability than CD133- cells and promote radioresistance in human hepatocellular carcinoma [7-8]. In addition, radioresistance has been observed in $\mathrm{CD}_{133^{+}}$glioma stem cells [9-10]. Thus, it is of great theoretical and practical value to develop novel radiosensitizers for CSCs.

Many studies are conducted to develop novel radiosensitizers, in which natural drugs have drawn great interest because of their low toxicity and low cost. Polydatin (PD), a component of Polygonum cuspidatum, is a glycoside of resveratrol and also known as 3,4,5'-Trihydroxy-stilbene-3- $\beta$-D-mono-Dglucoside. PD is found in grape, peanut, hop cones, and cocoa-containing products, and exhibits diverse biological functions, including anti-platelet aggregation, anti-oxidation, heart protection, anti-inflammation, anti-tumor and immunoregulation [11-16]. However, it is unclear whether PD involves in enhancing radiosensitivity and its molecular mechanism. Therefore, the present study aims to investigate whether $\mathrm{PD}$ can decrease the radiation resistance of CRC and its underlying mechanism. This study will provide experimental basis for developing $\mathrm{PD}$ as a novel radiosensitizer for CRC.

\section{Materials and methods}

\section{Animals}

Male C57BL/ 6 mice aged 6 weeks and weighing between 20 and $25 \mathrm{~g}$ were purchased from Shanghai Slack laboratory animal Co. Ltd. Animals were kept in Suzhou University Animal Center under SPF conditions. Mice handling procedures were reviewed and approved by the Animal Care/User Ethics Committee of Soochow University, Suzhou City, P. R. China. The experimental procedures for all mice were performed in accordance with the Regulations for the Administration of Affairs Concerning Experimental Animals approved by the State Council of People's Republic of China.

\section{Reagents}

PD was purchased from Meilun Inc. Ki-67 antibody was purchased from BD Bioscience (USA). Cleaved Caspase- 3 antibody was purchased from Cell Signaling (USA). CD31 antibody was purchased from Abcam (UK). Notch1 and cleaved Notch1 antibody was purchased from Cell Signaling Technology (USA). Azoxymethane (AOM) was purchased from Sigma (USA). Dextran sodium sulfate (DSS) was purchased from MP Biomedicals (USA). Annexin-V-FITC apoptosis detection kit and CCK-8 kit were purchased from Biotool (USA). N2 supplement, B27 supplement, EGF, noggin, Advanced DMEM/F12 and bFGF were purchased from Life Technologies (USA). CellTiter-Glo®3D cell viability detection kit was purchased from Promega (USA). k02288 (K), a highly selective inhibitor of BMP type I receptor with an IC50 of $6.4 \mathrm{nM}$ for ALK6, was purchased from Selleck. Magnetic beads coated with anti-Lgr5 antibody were purchased from Miltenyi Biotec (Germany). Flow cytometer was purchased from Beckman (USA). Philips SL18 Medical X-ray accelerator was purchased from Berkshire (UK). Multifunctional microplate reader was purchased from Molecular Devices (USA). Microscope was purchased from Olympus (Japan). X-ray radiometer was purchased from Radsource.

\section{Establishment of AOM/DSS-induced CRC model}

The mouse model of CRC induced by AOM/DSS was established as previously described [17]. Fifty C57BL/ 6 mice aged 6 weeks were intraperitoneally injected with AOM $(10 \mathrm{mg} / \mathrm{kg})$. Subsequently, mice were given drinking water for 7 days and fed with $2 \%$ DSS dissolved in drinking water for another 7 days; this procedure was repeated for three times and lasted for 10 weeks (Fig. 1A).

\section{Radiation and drug administration}

After establishment of the C57BL/6 mouse model of CRC, mice were divided into two parts: in part one, animals were used for collecting samples after radiation; in part two, mice were subject to survival analysis after radiotherapy. Each part of mice was randomly divided into 4 groups $(n=6)$ : control, PD alone, ionizing radiation (IR) alone, combination of PD and IR. Thirty minutes before IR, mice were intraperitoneally injected with $\mathrm{PD}$ at the dose of $25 \mathrm{mg} / \mathrm{kg}$ in PD and IR group. Abdominal exposure to X-ray of $6 \mathrm{MV}$ was conducted in Suzhou Kowloon Hospital with a total dose of 10 Gy and a dose rate of 200 cGy/min using a Philips SL18 linear accelerator. The radiation procedure was performed once a week with a total of 4 times. 
The cultured CRC cells were exposed to X-ray with a total dose of $10 \mathrm{~Gy}$ and a dose rate of 1.2 Gy/min using an X-ray radiometer (Radsource) at Jiangsu Province Key Laboratory of Radiation Medicine and Prevention, Soochow University.

\section{Sampling and survival analysis}

Mice used for survival analysis were daily observed after radiotherapy and their survival rate was recorded. Other mice were sacrificed 4 weeks after radiotherapy. The colorectum (from ileocecum to anus) were collected, washed with cold PBS, and fixed in $10 \%$ paraformaldehyde for subsequent experiments.

\section{Calculation of tumor number and volume}

The colorectum was collected and longitudinally dissected to count the tumor number. Tumor volume was calculated as $V=a \times b^{2} / 2$, where a represents the longer axis diameter and $b$ was the shorter axis diameter. Mice were divided in two groups based on tumor volume ( $\leq 5 \mathrm{~mm}^{2}$ and $>5 \mathrm{~mm}^{2}$ ) and the percentage of mice in each group was calculated.

\section{HE staining}

Colorectal tumor samples were fixed in paraformaldehyde, trimmed, dehydrated, embedded in paraffin and cut into slices. The slices were dried at $70^{\circ} \mathrm{C}$ in an oven for $30 \mathrm{~min}$, dewaxed three times in xylene for $5 \mathrm{~min}$ each, hydrated in graded concentrations of ethanol at $100 \%, 95 \%, 90 \%$ and $85 \%$ for $1 \mathrm{~min}$ each, stained with hematoxylin for $3 \mathrm{~min}$, treated by ethanol $(100 \%)$ for $1 \mathrm{~min}$, stained with eosin for 20s, dehydrated by graded concentrations of ethanol $(75 \%, 80 \%, 85 \%, 90 \%, 95 \%$ and $100 \%)$ for 1 min each and mounted to slides. Lastly, the slices were observed under a microscopy.

\section{Immunohistochemistry}

Intestinal tissue sections were dried at $70^{\circ} \mathrm{C}$ in an oven for $1 \mathrm{~h}$, dewaxed three times in xylene for $5 \mathrm{~min}$ each, hydrated in graded concentrations of ethanol $(100 \%, 95 \%, 90 \%$ and $85 \%$ ethanol for $5 \mathrm{~min}$ each), washed twice in water for $5 \mathrm{~min}$ each, treated with ethylenediaminetetraacetic acid $(1 \mathrm{mM})$ for antigen retrieval, washed three times in phosphate buffered solution with $0.05 \%$ Tween 20 (PBST) for $5 \mathrm{~min}$ each, and blocked in $5 \%$ bovine serum albumin (BSA) for 1h. Then, sections were incubated with Cleaved caspase3 (1:800) and Ki67 (1:200) antibodies overnight at $4^{\circ} \mathrm{C}$. After three 15-min washes in PBST, samples were incubated with Horseradish Peroxidase (HRP)-labeled secondary antibodies for $30 \mathrm{~min}$, washed in PBST for three times (10min each), and stained with diaminobenzidine (DAB) and counterstained with hematoxylin for 40s. Finally, the sections were dehydrated in graded concentrations of ethanol at $85 \%, 90 \%, 95 \%$ and $100 \%$, mounted on slides and observed under a microscopy.

For Ki67 staining results, "+" indicates that the number of positive cells in colorectal tissue in a microscope field is less than 20 ; "++" indicates that the number of positive cells is $20-50$; "+++" indicates that the number of positive cells is in 50-100; "++++" indicates that positive cells are distributed throughout vision.

\section{Cell proliferation assay}

Cells were seeded in a 96-well plate and treated with PD at different doses $(0 \mu \mathrm{M}, 20 \mu \mathrm{M}, 40 \mu \mathrm{M}, 60 \mu \mathrm{M}$, $80 \mu \mathrm{M}, 100 \mu \mathrm{M}$ and $120 \mu \mathrm{M})$. After culture for $24 \mathrm{~h}, 48 \mathrm{~h}$ and $72 \mathrm{~h}, 10 \mathrm{\mu l}$ of CCK-8 reagents were added and the absorbance at $450 \mathrm{~nm}$ was measured after $2 \mathrm{~h}$ using a microreader. For combined therapy, PD was added in the plates $30 \mathrm{~min}$ before $\mathrm{X}$-ray radiation with a total dose of $10 \mathrm{~Gy}$, and cell proliferation was measured at 24h, $48 \mathrm{~h}$ and $72 \mathrm{~h}$.

\section{5-Bromo-2-Deoxyuridine (BrdU) staining}

Cells were seeded in a six-well plate and treated with PD at $40 \mu \mathrm{M}$ alone, radiation alone or in combination. After culture for $48 \mathrm{~h}, 30 \mu \mathrm{M}$ BrdU were added for 4 hours. Harvest cells and wash cells in $1 \times$ PBS. Dislodge cell pellet and add ice-cold $70 \%$ ethanol, incubate at $-20^{\circ} \mathrm{C}$ for at least 2 hours. Dislodge cell pellet and add $2 \mathrm{~N} \mathrm{HCl}$ and incubate for 20 minutes at room temperature. Dislodge cell pellet and add $2 \mathrm{ml}$ of $0.1 \mathrm{M} \mathrm{Na}_{2} \mathrm{~B}_{4} \mathrm{O}_{7}$ for 10 minutes at room temperature. Wash cells in $1 \times$ PBS and centrifuge for 5 minutes at $1500 \mathrm{rpm}$. Discard supernatant. Add BrdU antibody at appropriate concentration and incubate for 20 minutes at room temperature. Stain DNA by adding DAPI. Wait for 5 minutes prior to acquiring samples on flow cytometer.

\section{Apoptosis assay}

Cells were seeded in six-well plates and treated with PD alone $(40 \mu \mathrm{M})$, radiation alone $(10 \mathrm{~Gy})$ or in combination. PD was added $30 \mathrm{~min}$ before radiation and $48 \mathrm{~h}$ after radiation, cells were collected, digested in trypsin, washed twice in cold PBS and centrifuged. Cells were re-suspended in 100ul of $1 \times$ Binding Buffer and incubated with 5ul of Annexin V-FITC and 5ul of PI Staining Solution for $15 \mathrm{~min}$. Then, $400 \mathrm{ul}$ of $1 \times$ Binding Buffer were added to plates and samples were detected using a flow cytometer within $1 \mathrm{~h}$.

\section{Magnetic cell sorting of Lgr5+ CSCs}

CT26 cells $\left(1 \times 10^{7}\right)$ were filtered through a $40 \mu \mathrm{m}$ filter, centrifuged at $300 \mathrm{~g}$ for $10 \mathrm{~min}$, and incubated with 50ul of Lgr5-biotin antibody (1:10) and 450ul of 
cell sorting buffer at $4^{\circ} \mathrm{C}$ for $10 \mathrm{~min}$. Cells were washed twice in $1-2 \mathrm{ml}$ of cell sorting buffer, centrifuged at $300 \mathrm{~g}$ for $10 \mathrm{~min}$, and re-suspended in $80 \mathrm{ul}$ of cell sorting buffer; cells were incubated with $20 \mathrm{ul}$ of anti-biotin magnetic beads at $4^{\circ} \mathrm{C}$ for $15 \mathrm{~min}$, washed in $1-2 \mathrm{ml}$ of cell sorting buffer, and centrifuged at $300 \mathrm{~g}$ for $10 \mathrm{~min}$. After discarding the supernatants, cells were re-suspended in cell sorting buffer and added to a LS column. Unlabeled cells flowing from the LS column were collected and the LS column was washed three times with $3 \mathrm{ml}$ of cell sorting buffer. Finally, $5 \mathrm{ml}$ of cell sorting buffer were added and $\mathrm{Lgr}^{+} \mathrm{CSC}$ s were harvested from the LS column.

\section{D culture and passage of Lgr5+ CSCs}

The sorted colorectal CSCs were seeded in a six-well plate and cultured in tumor sphere media (2ml/well) for 7 days. The second passage cells were used for study. For cell passage, sphere cells were collected and digested in $1 \mathrm{ml}$ of pre-heated trypsin containing EDTA. Sphere cells were suspended using a micropipettor before addition of $5 \mathrm{ml}$ of cold buffer solution to terminate digestion. After centrifugation at $350 \mathrm{~g}$ for $5 \mathrm{~min}$, the supernatants were discarded and sphere cells were counted and passaged after addition of $1 \mathrm{ml}$ of tumor sphere media.

\section{Cell viability assay}

Colorectal CSCs were seeded in a low adhere 96-well plate and treated with PD alone, radiation alone or in combination. CellTiter-Glo ${ }^{\circledR} 3 \mathrm{D}$ cell viability assay was performed at day 3, 5 and 7 after treatment. To be brief, CellTiter-Glo ${ }^{\circledR} 3 \mathrm{D}$ reagents were dissolved overnight at $4^{\circ} \mathrm{C}$ and were brought to room temperature in $22^{\circ} \mathrm{C}$ water baths. Colorectal CSCs were also prepared to room temperature to equilibrate for $30 \mathrm{~min}$ and lyzed in $100 \mathrm{ul} /$ well of CellTiter-Glo ${ }^{\circledR}$ 3D reagents for $25 \mathrm{~min}$ under room temperature. Finally, the optical density (OD) values were determined using a multifunctional microplate reader.

\section{Western blot}

The CSCs were seed in a 6-well plate and treated with $\mathrm{PD}$ at $40 \mu \mathrm{M}$ alone, radiation alone or in combination. After culture for 5 days, CSCs were collected, washed with cold PBS, lyzed in $150 \mu \mathrm{l}$ of lysis buffer, and centrifuged at $4^{\circ} \mathrm{C}$ at $12,000 \mathrm{rpm}$ for 5 min. Protein concentration was determined by BCA assay and equal amounts of cell proteins were separated by Sodium Dodecyl Sulphate -Polyacrylamide gel electrophoresis (SDS-PAGE). The proteins on the gels were electro-transferred to polyvinylidene fluoride (PVDF) membrane, washed three times with PBS, blocked in 5\% nonfat milk for 1 h. Subsequently, PVDF membrane was incubated with primary antibodies at $4^{\circ} \mathrm{C}$ overnight. Following three 15-min washes in tris-buffered saline and Tween 20 (TBST), the membrane was incubated with the corresponding secondary antibodies. Finally, the blots were visualized using the enhanced chemiluminescence system.

\section{Statistical analysis}

Survival analysis was performed using the Kaplan-Meier method. Expression of Ki67 in colorectal tumor samples in different groups was compared using CMHx2 test. Other experimental data were presented as means \pm standard deviation $(\bar{x}$ \pm SD) and differences between groups were analyzed using $t$ test. $\mathrm{P}<0.05$ was considered as statistically significant. The marked * in the text means that there is a statistical difference. * means $\mathrm{P}<0.05$.

\section{Results}

\section{IR combined with PD significantly prolonged the survival time of CRC mice}

In order to investigate the radiosensitizing effect of PD on CRC mice, the survival time of mice in each group was observed. As shown in Figure 1B, combination of PD and IR significantly prolonged the survival time of mice compared with mice in the IR alone group.

\section{IR combined with PD decreases tumor number and volume in CRC mice}

Next, we studied the effect of IR combined with $\mathrm{PD}$ on tumor number and volume in CRC mice. In Figure 2A, it can be observed the formation of colorectal adenoma structure, so C57BL/6 mouse model of colorectal cancer was successful. As shown in Figure $2 \mathrm{~B}$ and $2 \mathrm{C}$, IR alone, $\mathrm{PD}$ alone, or in combination significantly decreased tumor number compared with the control group. In PD combined with IR group, mice with tumor volume $>5 \mathrm{~mm}^{2}$ or $<$ $5 \mathrm{~mm}^{2}$ accounted for the smallest $(15 \%)$ and largest proportion, respectively (Fig. 2D). These data suggest that PD in combination with IR significantly reduce tumor number and volume in CRC mice.

\section{PD in combination with IR inhibits cell proliferation and induces cell apoptosis in CRC mice}

The above-mentioned data indicate that PD may be an effective radiosensitizer by prolonging survival time and reducing tumor number and volume. Next, we observed the effect of PD combined with IR on proliferation of CRC. As shown in Figure 3A and 3B, we detected a significant increase of $\mathrm{Ki}^{6} 7^{+}$cells in IR group compared to the PD combined IR group. Moreover, the number of cleaved casapse- $3^{+}$cells in 
each field increased by $11 \pm 1$ in PD combined IR group compared to the IR group (400× magnification) (Fig $3 \mathrm{~A}$ and $3 \mathrm{D})$. The average number of cleaved casapse- $3^{+}$cells in CRC in PD combined IR group was $40 \pm 1$ with the highest apoptotic rate. These data suggest that combination of PD and IR inhibits cell proliferation and promotes apoptosis of CRC cells. PD alone had no obvious inhibitory effect on tumor cell proliferation, but it could promote CRC cell apoptosis.
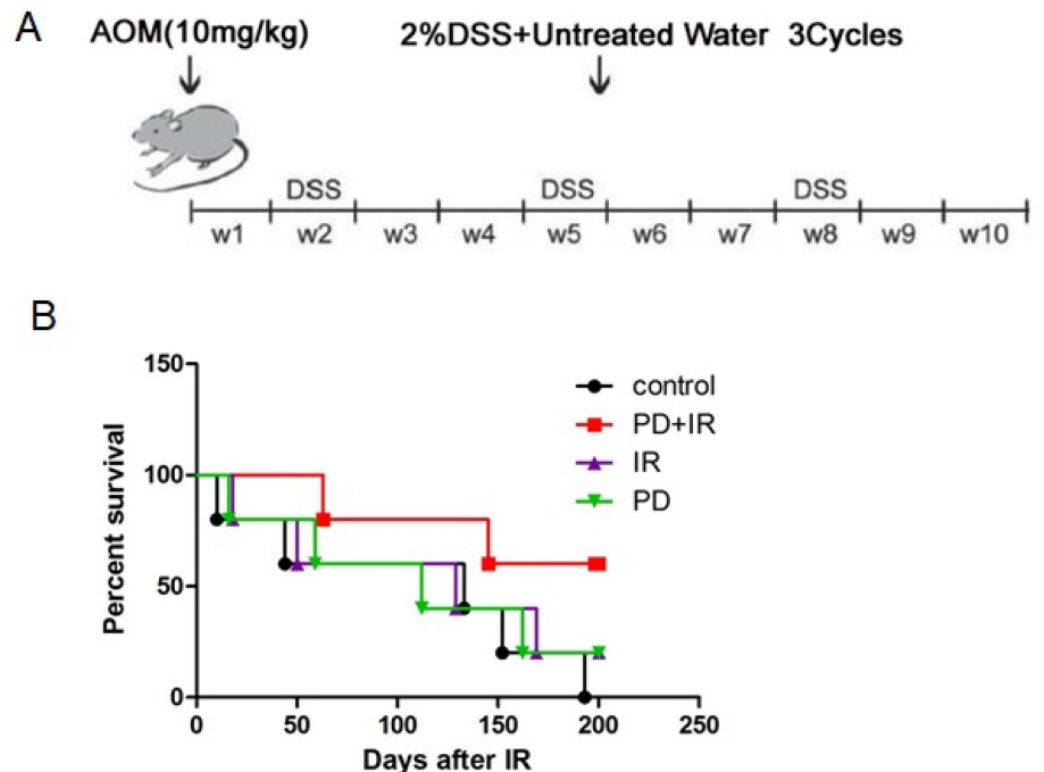

Fig. 1. Establishment of orthotopic C57BL/6 mouse model of CRC and effects of PD combined with IR on survival rates of mice. (A) C57BL/6 mice aged 6 weeks were intraperitoneally injected with AOM $(10 \mathrm{mg} / \mathrm{kg})$. Subsequently, mice were given drinking water for 7 days and fed with $2 \%$ DSS dissolved in drinking water for another 7 days; this procedure was repeated for three times and lasted for 10 weeks. (B) Each group consisted of 6 mice. The radiation therapy was performed at a total dose of $10 \mathrm{~Gy}$ and a dose rate of $200 \mathrm{cGy} / \mathrm{min}$, and once a week for a total of 4 times. The survival time of each mouse was recorded and analyzed for statistical significance after 200 days. PD+IR group compared with another group, $P<0.05$.

A control

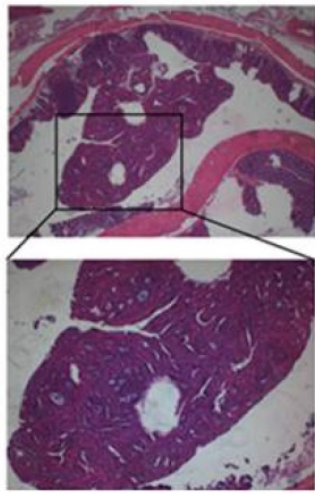

control

B

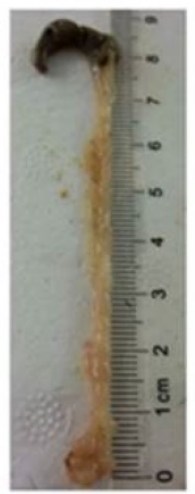

PD

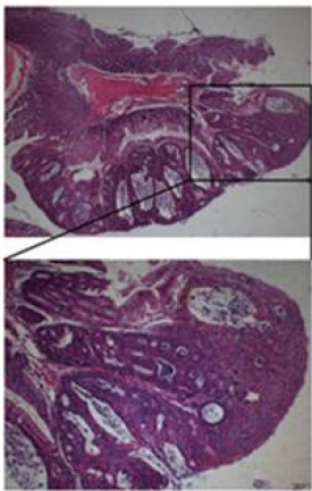

PD
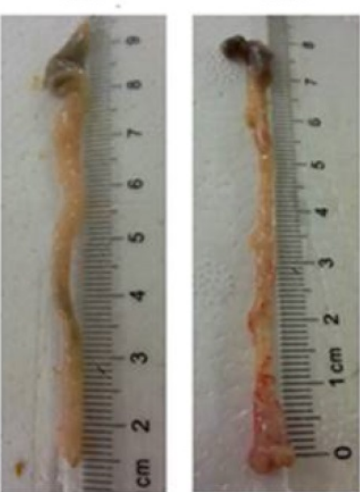

$\mathrm{PD}+\mathrm{IR}$

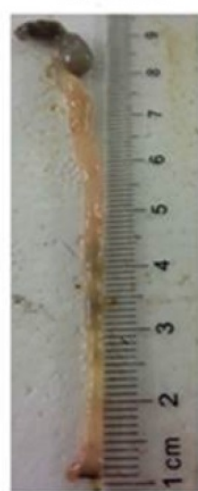

$P D+I R$
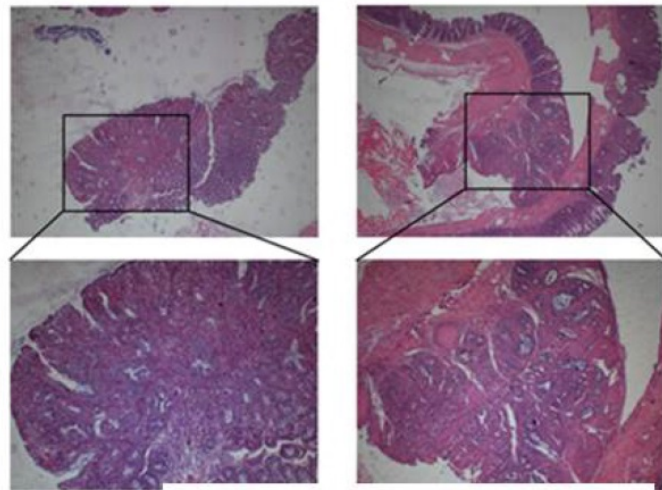

C

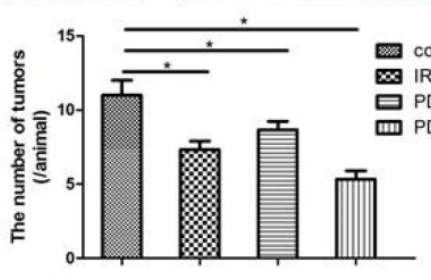

D

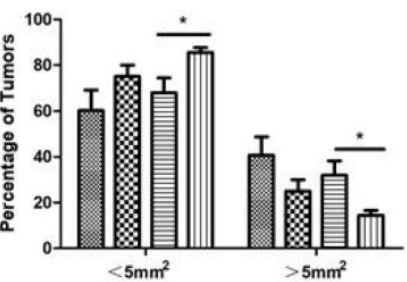

Fig. 2. Effect of PD in combination with IR on tumor number and volume. (A) HE staining of tumor samples in the orthotopic mouse model of CRC; upper 40×, lower 200×. (B) Representative image of tumors of mice in each group. (C) Tumor number. (D) Tumor volume. ${ }^{*} P<0.05, n=6$. 
A
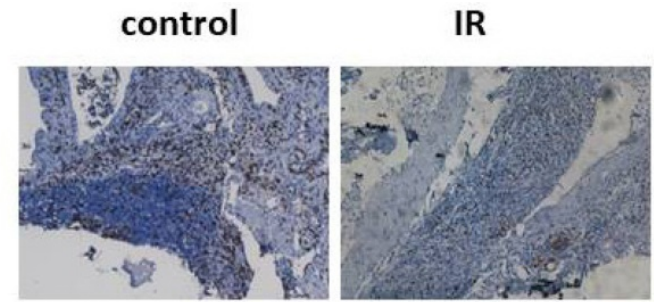

PD

PD+ IR

Ki67
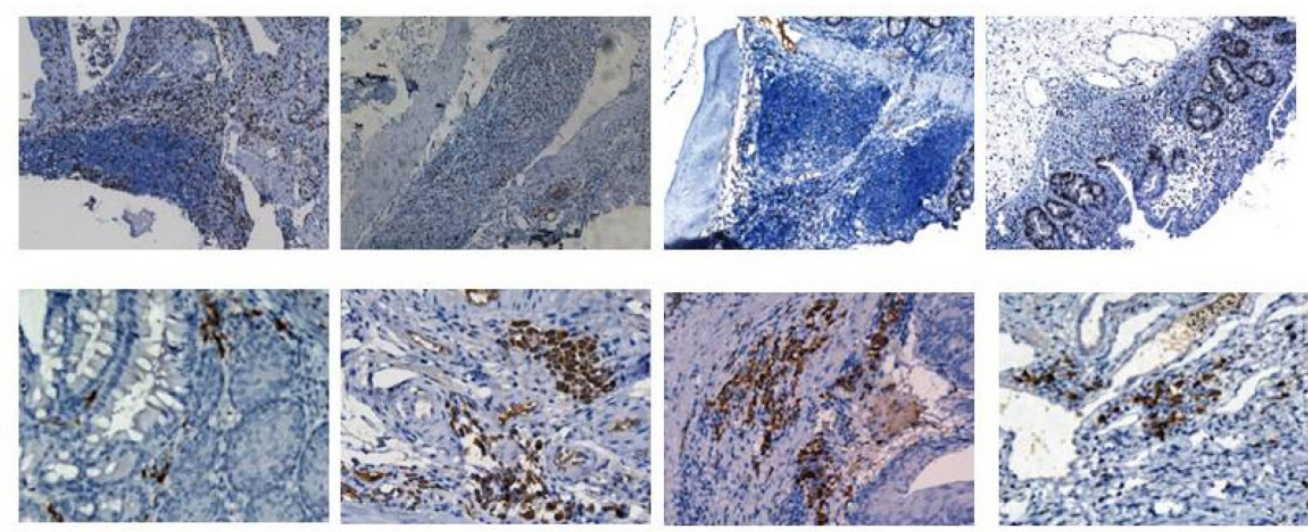

\section{cleaved \\ caspase-3}

\begin{tabular}{|c|c|c|c|c|c|c|}
\hline & + & ++ & +++ & ++++ & total & mean \\
\hline control & 10 & 20 & 5 & 2 & 37 & 1.97 \\
\hline$P D+1 R$ & 25 & 20 & 2 & 0 & 47 & 1.51 \\
\hline IR & 17 & 24 & 5 & 0 & 46 & 1.74 \\
\hline PD & 25 & 13 & 3 & 0 & 41 & 1.46 \\
\hline
\end{tabular}
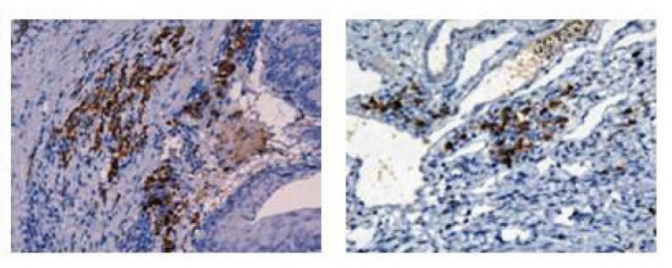

C

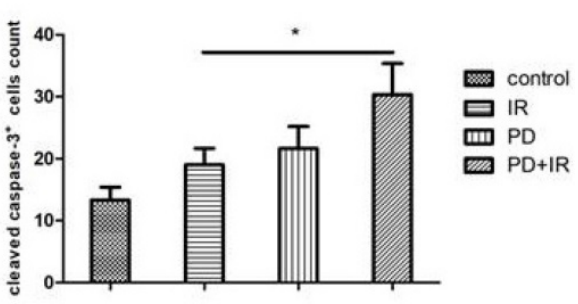

Fig. 3. Immunohistochemical staining of Ki67 and cleaved caspase- 3 in CRC cells. (A) Representative images of Ki67+ and cleaved caspase-3+ cells, $400 \times$. (B) Number of Ki67+ cells, "+" indicates that the number of positive cells in colorectal tissue in a microscope field is less than 20 ; "++" indicates that the number of positive cells is $20-50$; "+++" indicates that the number of positive cells is in $50-100$; "++++" indicates that positive cells are distributed throughout vision. $C M H \times 2$ test, $P D+I R$ group vs. IR group, $P<0.05$. (C) Number of cleaved caspase- $3^{+}$cells, $* P<0.05, \mathrm{n}=6$.

\section{Effects of PD in combination with IR on proliferation and apoptosis in different CRC cell lines}

These in vivo experiments confirm the radiosensitizing effect of $\mathrm{PD}$ on $\mathrm{CRC}$. We further evaluated the effects of PD on proliferation and apoptosis in different CRC cell lines. As a result, treatment of CT26 cells with PD at the dose of $20-120 \mu \mathrm{M}$ for $24 \mathrm{~h}, 48 \mathrm{~h}$ and $72 \mathrm{~h}$ had no obvious effects on tumor cell proliferation (Fig. 4A). Combined

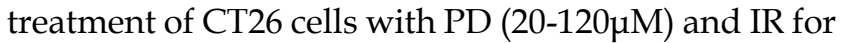
$48 \mathrm{~h}$ and $72 \mathrm{~h}$ significantly inhibited tumor cell proliferation compared to the control group (Fig. 4B-D). And, we used the BrdU method to detect the effect of PD combined radiation on cell proliferation (Fig. 4E). The result also can be seen that PD combined radiation inhibited cell proliferation. In addition, IR induced apoptosis in CT26 cells and the apoptotic rate was even higher in the combination group (Fig. $4 \mathrm{~F}$ and $G)$.

Similar effects were also observed in HCT116 cells: treatment of HCT116 cells with PD $(20-120 \mu \mathrm{m})$ for $24 \mathrm{~h}, 48 \mathrm{~h}$ and $72 \mathrm{~h}$ had no inhibitor effects on tumor cell proliferation (Fig. 5A); combined treatment of HCT116 cells with PD $(20-120 \mu \mathrm{M})$ and IR for $48 \mathrm{~h}$ and 72h significantly suppressed tumor cell proliferation (Fig. 5B-D). Moreover, combination of PD and IR obviously promoted the apoptosis of HCT116 cells (Fig. 5E and F).

Taken together, PD combined with IR both inhibits proliferation and induces apoptosis in CT26 and HCT116 cells, thereby sensitizing tumor cells to IR therapy.

\section{Effect of PD combined with IR on proliferation of Lgr5+ CSCs}

Figure 6A illustrated the representative image of Lgr5 ${ }^{+}$CSCs spheres with different diameters. At 3, 5 and 7 days, Lgr5 ${ }^{+}$CSCs spheres in the control group had the largest diameter; while their diameters significantly decreased in PD group $(P<0.05)$. Compared to the IR group, IR combined treatment with PD for 3, 5 and 7 days significantly decreased the diameter of CSCs spheres by $32 \pm 1 \mu \mathrm{m}, 55 \pm 1 \mu \mathrm{m}$ and $53 \pm 1 \mu \mathrm{m}$, respectively.

The ATP activity of Lgr5 ${ }^{+}$CSCs was shown in Figure 6B. In the control group, $\mathrm{Lgr5}^{+} \mathrm{CSC}$ s exhibited the highest activities at day 3,5 and 7days. Compared to the IR group, combined treatment with PD and IR for 3,5 and 7 days decreased the OD values by $1493 \pm 1,3717 \pm 1$ and $1649 \pm 1$, respectively. These data suggest that $\mathrm{PD}$ at the dose of $40 \mu \mathrm{M}$ inhibits proliferation of $\mathrm{Lgr}^{+}$CSCs; PD combined with IR remarkably suppresses $\mathrm{Lgr}^{+} \mathrm{CSC}$ s proliferation and thereby sensitizes tumor cells to IR. 
A

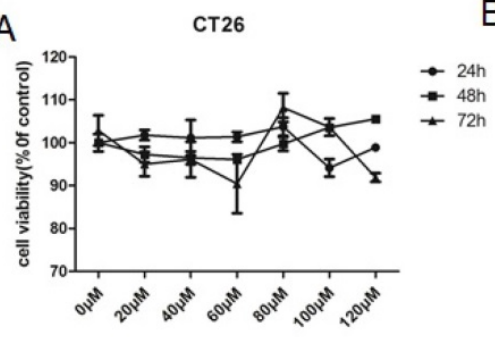

D

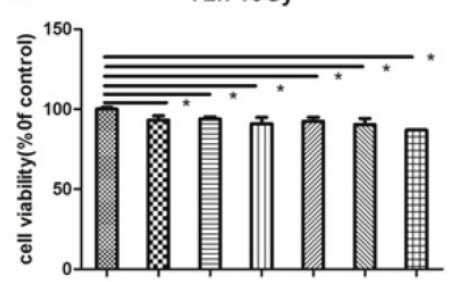

B

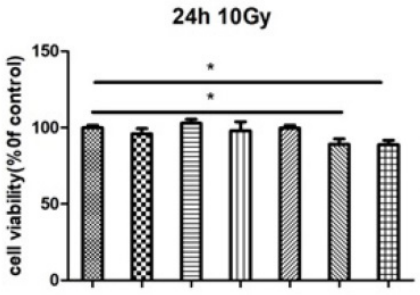

E

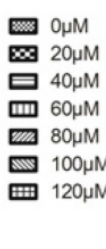

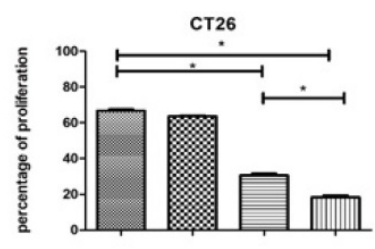

C

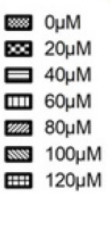

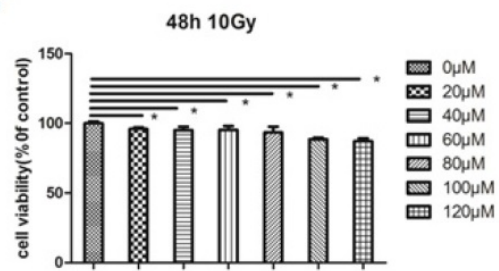

$\mathrm{F}$
G

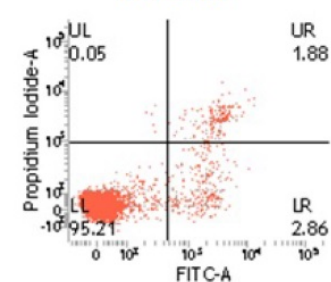

PD

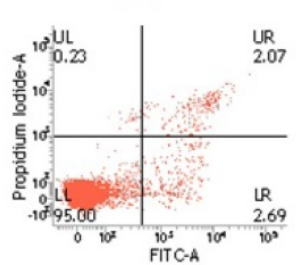

IR

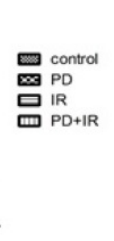

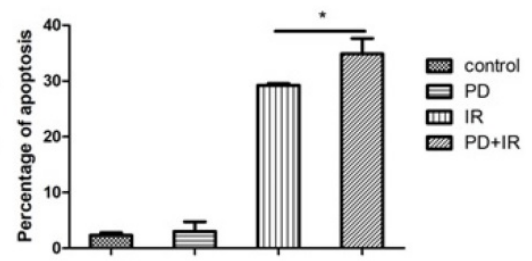

Fig. 4. Effects of PD on CT26 cell proliferation and apoptosis. (A) Effect of PD at different doses on proliferation of CT26 cells. (B) CT26 cell proliferation was measured $24 \mathrm{~h}$ after treatment with PD combined with IR. (C) CT26 cell proliferation was measured 48h after treatment with PD combined with IR. (D) CT26 cell proliferation was measured $72 \mathrm{~h}$ after treatment with PD combined with IR. (E) CT26 cell proliferation was measured 48h after treatment with PD combined with IR using BrdU staining method. (F)

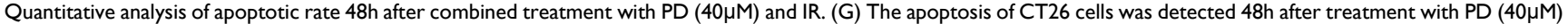
combined with IR.* $P<0.05, n=3$. Repeat three times for each experiment.

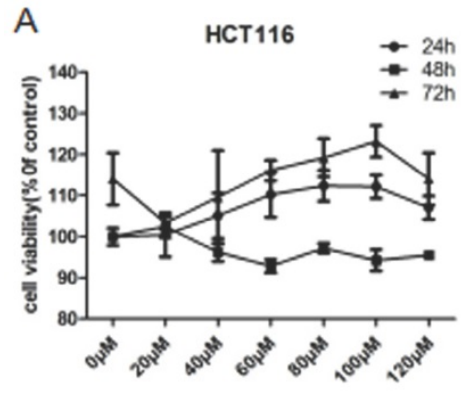

$\mathrm{D}$

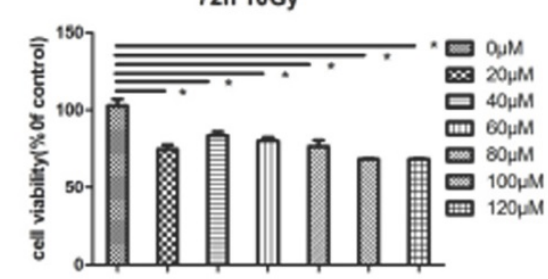

E
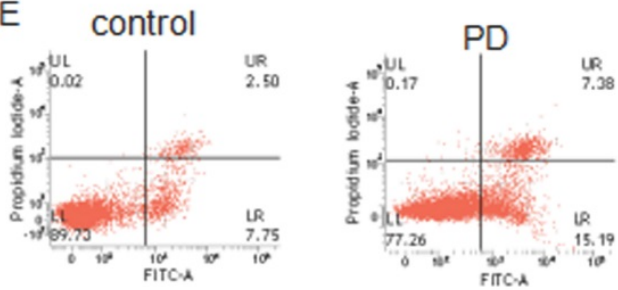

B

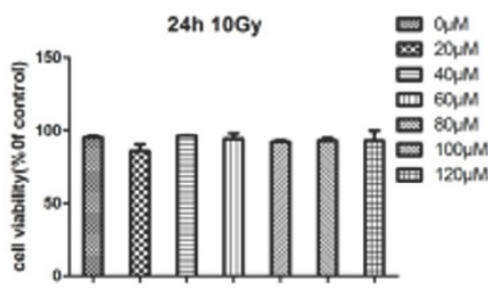

C

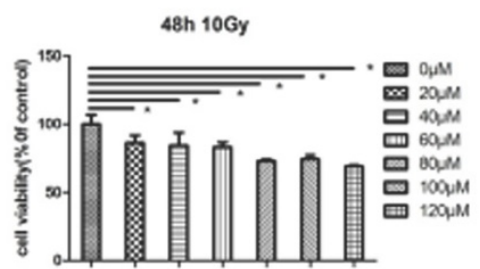

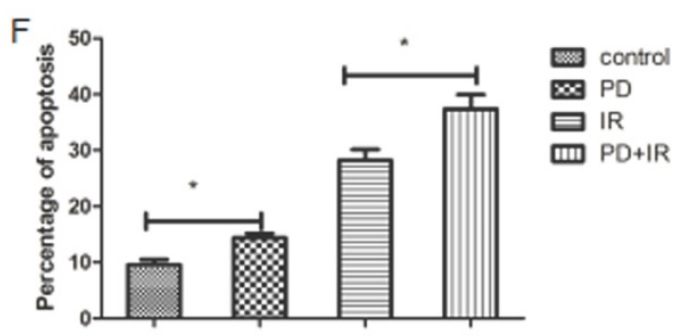
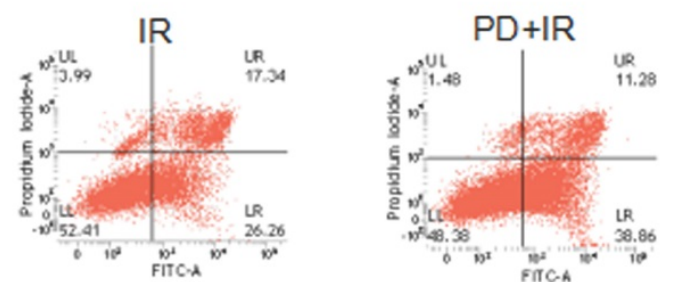

Fig. 5. Effects of PD on HCT1 16 cell proliferation and apoptosis. (A) Effect of PD at different doses on proliferation of HCT116 cells. (B) HCT116 cell proliferation was measured 24h after treatment with PD combined with IR. (C) HCT116 cell proliferation was measured 48h after treatment with PD combined with IR. (D) HCT116 cell proliferation was measured $72 \mathrm{~h}$ after treatment with PD combined with IR. (E) The apoptosis of HCT1 16 cell was detected 48h after treatment with PD (40 $\mu M$ ) combined with IR. (F) Quantitative analysis of apoptotic rate $48 \mathrm{~h}$ after combined treatment with PD $(40 \mu \mathrm{M})$ and IR. $* P<0.05, n=3$. Repeat three times for each experiment. 
A control
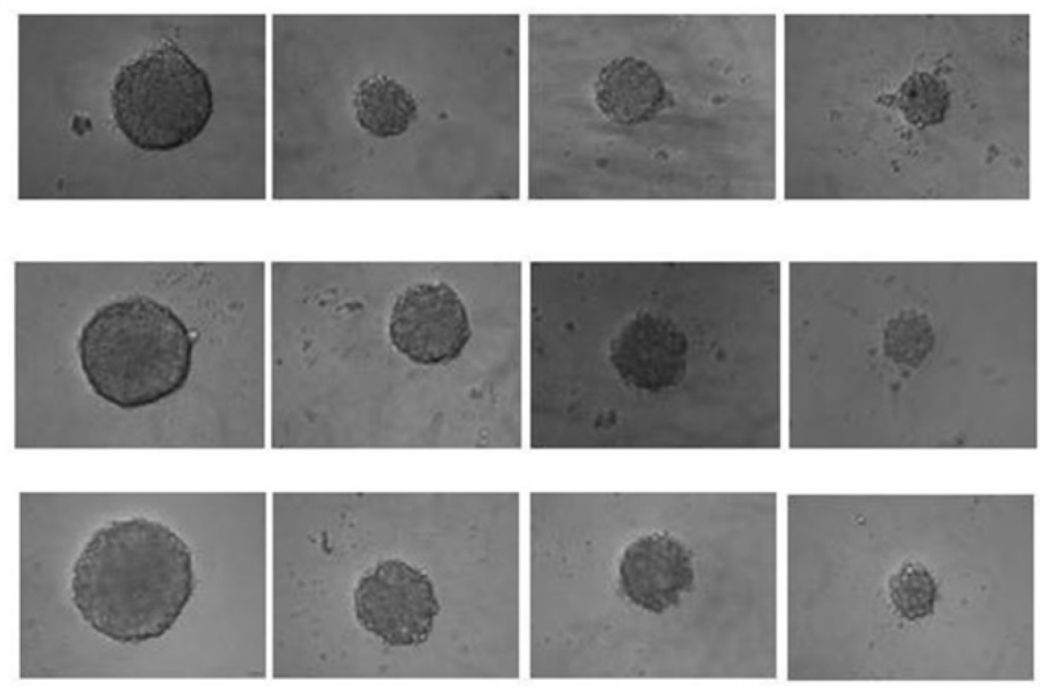

PD+IR
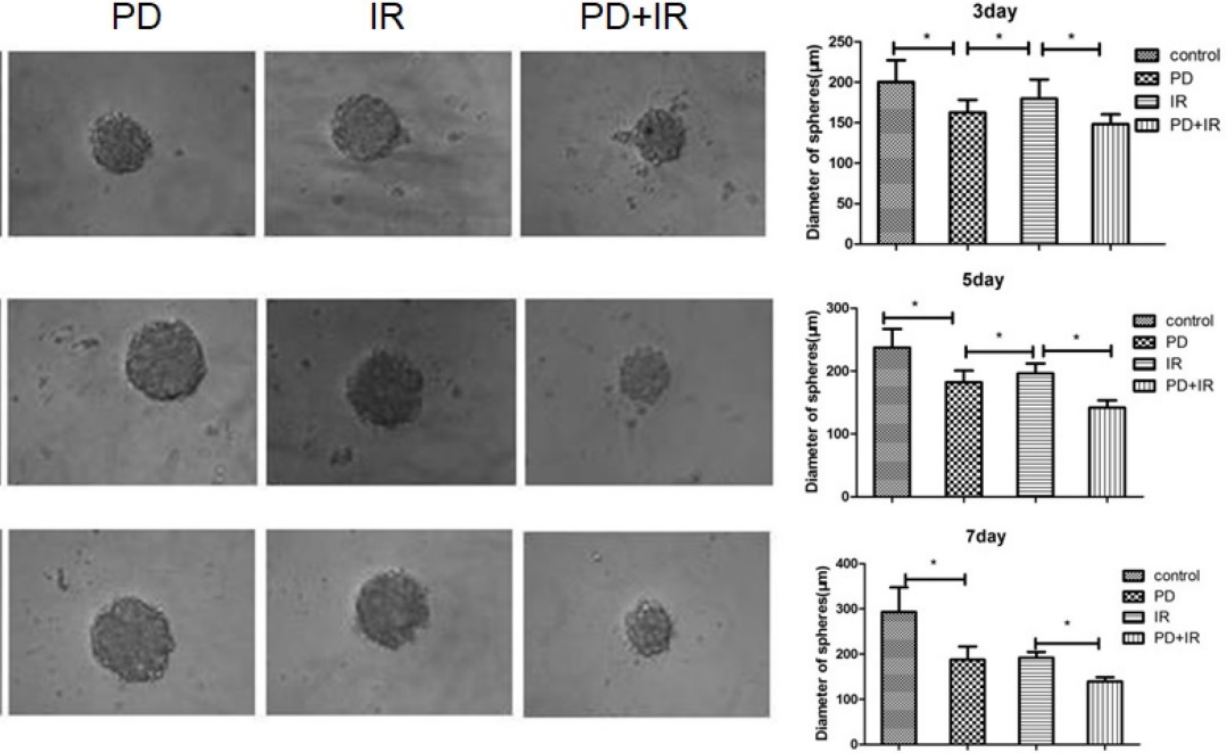

B
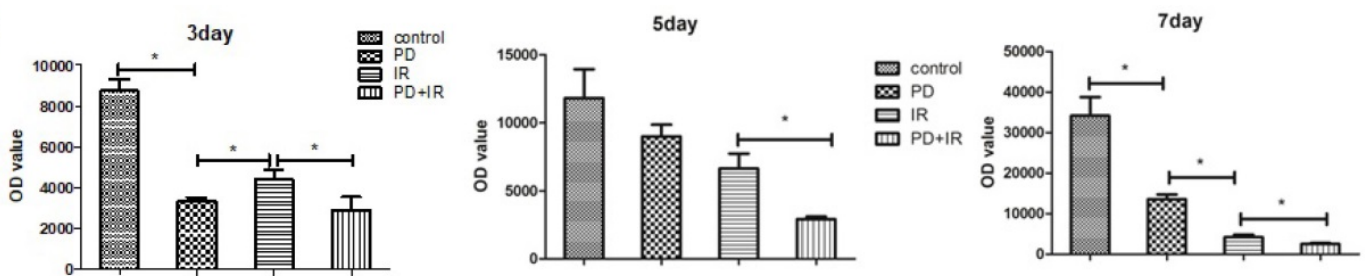

Fig. 6, Effects of PD on the sphere and activity of Lgr5+ CSCs. (A) Representative image of Lgr5+ CSCs spheres at day 3, 5 and 7. PD, 40 4 M; radiation dose, 10Gy. (B) Effects of $\mathrm{PD}$ on the activity of $\mathrm{Lgr} 5+$ CSCs. The activity of $\mathrm{Lgr} 5+\mathrm{CSCs}$ at 3, 5 and 7 days was detected using a Cell Titer-Glo $\otimes 3 D$ cell viability detection kit. $* P<0.05$, $\mathrm{n}=3$. Repeat three times for each experiment

\section{Effect of PD combined with IR on apoptosis of Lgr5+ CSCs}

The effect of PD combined with IR on apoptosis of Lgr5+ CSCs was shown in Figure 7. Compared to the control group, the apoptotic rate of $\mathrm{Lgr5}^{+} \mathrm{CSCs}$ treated by PD significantly increased, and CSCs in the combination group exhibited an even higher apoptotic rate. These results suggest that PD induces the apoptosis of $\mathrm{Lgr}^{+} \mathrm{CSC}$ and combined treatment increases the apoptotic rate of $\mathrm{Lgr}^{+} \mathrm{CSC}$ s to enhance the cytotoxic effect of radiation on tumor cells.

\section{BMP signaling mediates the radiosensitizing effect of PD on CRC}

Lgr5 is a marker of intestinal epithelial stem cells that participates in Wnt signaling to maintain self-renewal and stemness stem cells [18-20]. In addition, three other signaling pathways are involved in intestinal stem cell differentiation and maturation, i.e., BMP [21], phosphatidylinositol-4,5-bisphosphate 3-kinase (PI3K) [22] and Notch [23]. In order to determine the radiosensitizing mechanism of $\mathrm{PD}$, CSCs were treated with the type I BMP receptor inhibitor $\mathrm{K} 02288(6.4 \mathrm{nM})$ together with $\mathrm{PD} 30 \mathrm{~min}$ before radiation. As shown in Figure $8 \mathrm{~A}$ and $8 \mathrm{~B}$, compared to the PD combined with IR group, addition of $\mathrm{K} 02288$ increased the diameter of CSCs spheres at day 3, 5 and 7days, suggesting that K02288 attenuated the radiosensitizing effect of PD on Lgr5 ${ }^{+}$ CSCs via inhibition of BMP signaling pathway. Moreover, treatment with $\mathrm{K} 02288$ for 3, 5 and 7 days elevated the ATP activity of $\mathrm{Lgr}^{+}{ }^{+} \mathrm{CSC}$ compared to CSCs treated with PD and IR. These data suggest that PD sensitizes $\mathrm{Lgr5}^{+} \mathrm{CSC}$ s to radiation by BMP signaling pathway. We also detected the contributions of Notch pathways showed as Figure 8C. The results indicated that Notch pathways play no important role in PD working.

\section{Discussion}

CRC is a common gastrointestinal malignancy that threatens human life and health. Radiation therapy is one of the main treatment modalities for CRC, but radioresistance of CRC seriously affects the therapeutic efficacy and becomes a great challenge for successful treatment of patients with CRC. Therefore, adjunctive therapy (such as application of radiosensitizer) is often used to decrease the radioresistance and improve the radiosensitivity of tumors. Recently, the radiosensitizing potential of multiple drugs has been explored, including nitroimidazoles [24], cyclooxygenase COX-2 inhibitors [25], platinum compounds [26], natural 
drugs [27], and molecular targeted drugs [28]. However, there are no clinically validated radiation sensitizers so far. Among those radiosensitizers, natural drugs and their monomers have better application prospects due to their low toxicity, better therapeutic effect, easy accessibility and low cost.
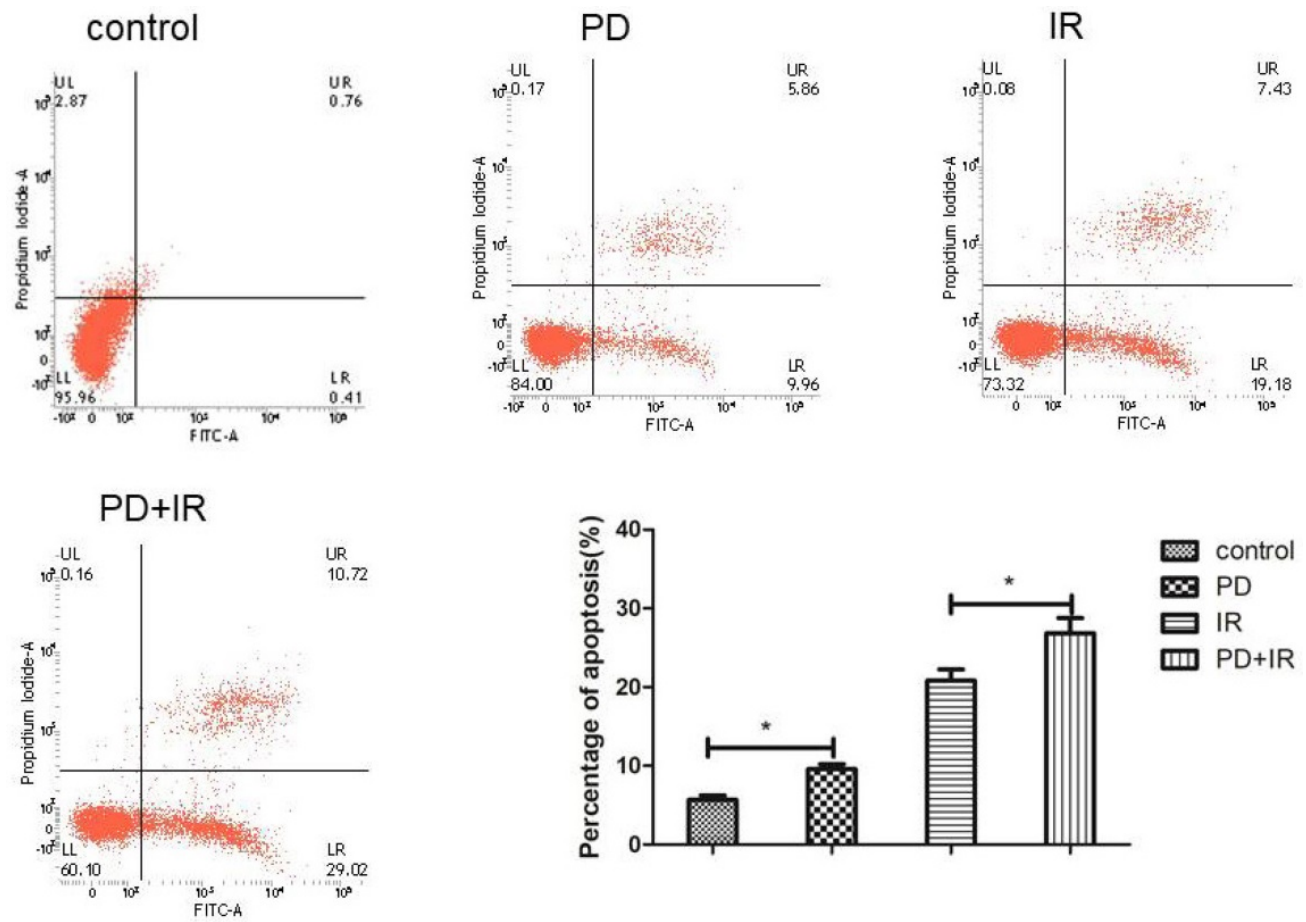

Fig. 7. Effects of PD $(40 \mu \mathrm{M})$ combined with IR (10Gy) on Lgr5+ CSCs apoptosis, * $P<0.05, n=3$. Repeat three times for each experiment

A
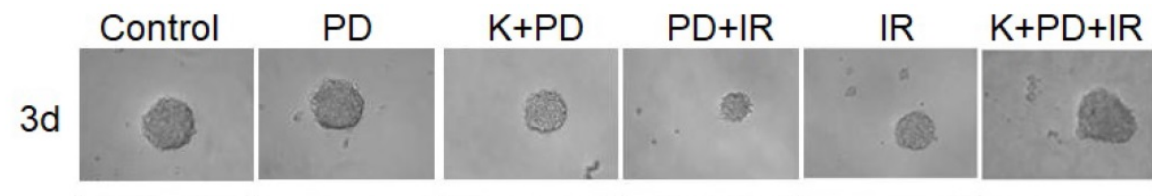

$5 d$
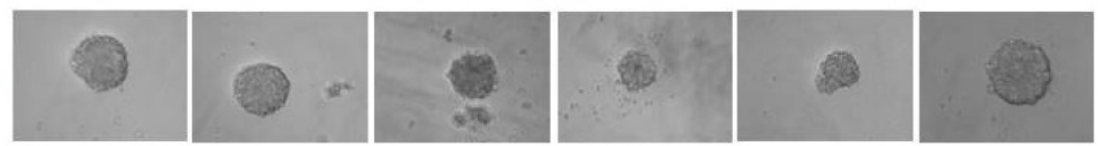

$7 d$
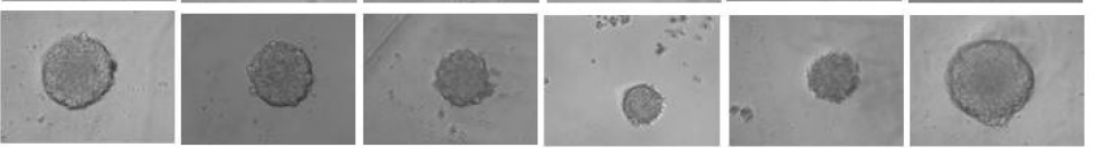

B
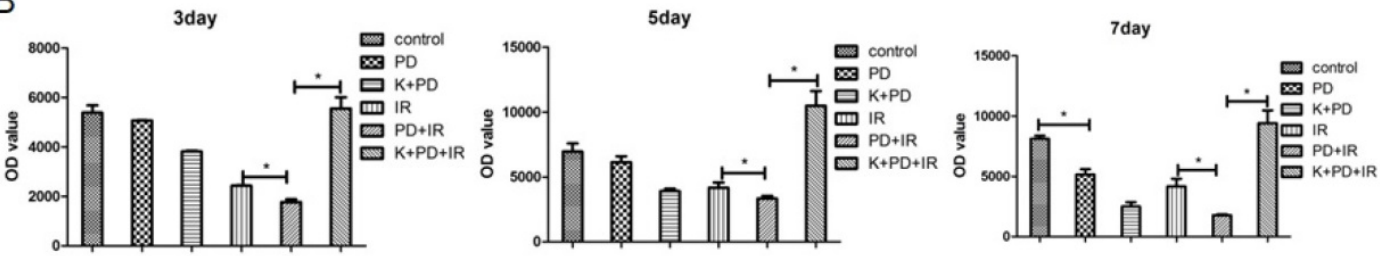

C

CSCs

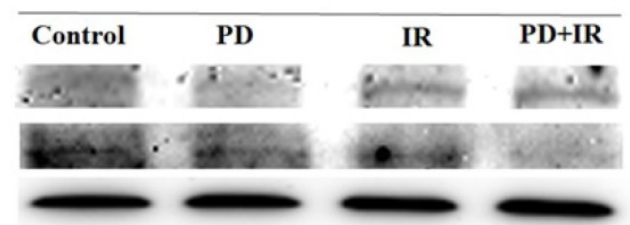

cleaved Notch1

Notch1

$\beta$-tubulin

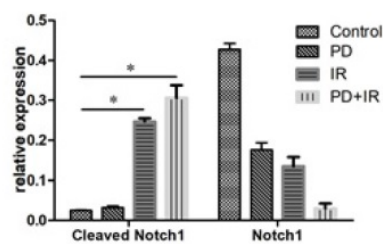

Fig. 8. BMP mediates the radiosensitizing effect of PD in CSCs. (A) Representative image of Lgr5+ CSCs spheres at day 3,5 and 7 days. (B) The activity of Lgr5+ CSCs at 3,5 and 7 days was detected using a Cell Titer-Glo ${ }^{R} 3 \mathrm{D}$ cell viability detection kit. K02288 (K), 6.4nM; radiation dose, 10Gy. (C) The contributions of Notch pathway were detected using western blot. $* \mathrm{P}<0.05, \mathrm{n}=3$. Repeat three times for each experiment. 
PD is the fourth monomer extracted from the root of Polygonum cuspidatum and is a natural precursor of resveratrol. Pharmacological studies have demonstrated that PD has diverse biological functions, such as inhibition of inflammation, immunoregulation, induction of apoptosis of tumor cells, protective effects against liver injury and cardiovascular disease [11-16]. Zhang et al have reported that PD could inhibit growth of lung cancer cells; moreover, PD induces apoptosis by up-regulating Bax and down-regulating $\mathrm{Bcl}-2$ and causes S-phase cell cycle arrest of A549 and NCI-H1975 cells [29]. In addition, PD induces cell cycle arrest and differentiation of human colorectal Caco-2 cells; moreover, PD causes Caco-2 cell death via induction of apoptosis [30]. In this study, PD in combination with radiotherapy could significantly prolong the survival time in mouse models of CRC, inhibit tumor cell proliferation, induce apoptosis and reduce the number and volume of tumors. In vitro experiments, Figure 4A and 5A show that PD has no significant inhibitory effect on the proliferation of HCT116 and CT26 cells, and there is no statistically significant difference between different concentrations of PD. However, from Figure 4 and Figure 5, PD can promote the apoptosis of colorectal cancer cells HCT116 and CT26. So, PD combined with radiotherapy can play a greater role in the killing of colorectal cancer, can inhibit its proliferation and promote its apoptosis. And, PD can inhibit the proliferation of $\mathrm{Lgr5}^{+} \mathrm{CSC}$ and promote their apoptosis. Taken together, these results confirm that PD can serve as a radiosensitizer for CRC.

Radiation resistance of tumor cells is closely related to DNA damage and repair, oxygen concentration in tumor microenvironment, and proliferation, differentiation and cell cycle distribution of tumor cells. However, the molecular mechanisms of radiation resistance have not been fully elucidated. Increasing evidence demonstrates that CSCs determine the fate and clinical outcome of tumors. The "CSCs hypothesis" believes that cancers are developed from and maintained by a small subset of cells-CSCs, which possess self-renewal properties and differentiate into the heterogeneous nontumorigenic cancer cell types [31]. Compared to the nontumorigenic cancer cells, CSCs have a higher ability of DNA repair and a stronger radioresistance, which makes CSCs a critical therapeutic target [32]. It is reported that CD49f and CD133 are overexpressed in cervical CSCs in which genes required for radioresistance are up-regulated, including components of the double-strand break (DSB) DNA repair machinery and the metabolism of reactive oxygen species (ROS) [33]. In addition, CD133+ liver CSCs have higher self-renewal ability than CD133liver CSCs and increase radiation resistance in human hepatocellular carcinoma [7-8]. Moreover, CD133+ CSCs exhibit radioresistant features in glioma [9-10]. It is reported that Lgr5, not Bmi1, is expressed in $74-85 \%$ cases of CRC, which is a surface marker of CRC stem cells [34-35]. Thus, we used Lgr5 as the marker of CRC stem cells to observe the radiosensitizing effect of PD on CRC. Results showed that combination with PD and radiotherapy obviously inhibited proliferation and decreased activity of CRC stem cell-derived spheres.

It is well known that intestinal stem cells are mediated by several signaling pathways including Wnt, BMP, PI3K and Notch signaling, which are closely related to radiation sensitivity [36-37]. In order to determine the radiosensitizing mechanism of PD, CSCs were treated with BMP signaling inhibitor (K02288) and their proliferation and activity were subsequently observed. Results showed that addition of K0228 attenuated the inhibitory effect of combined therapy on CSCs proliferation, suggesting that PD regulated CSCs radiosensitivity via BMP signaling pathway.

In summary, our study demonstrates that PD decreases radioresistance of CRC stem cells via BMP signaling pathway, thereby sensitizing tumor cells to radiotherapy. These results imply that PD may be developed as a radiosensitizer for treatment of CRC.

\section{Acknowledgements}

This study was supported by the National Natural Science Foundation of China (Grant No. 81372920); the Priority Academic Program Development of Jiangsu Higher Education Institutions; Defense basic research projects.

\section{Author contributions}

All the authors listed made substantial contributions to the manuscript and qualify for authorship, and no authors have been omitted. Conception and design: Jin-Bing Wang, Feng-Mei Cui; development of methodology and acquisition of data: Qiu Chen, Ya-Nan Zeng, Ke Zhang; analysis and interpretation of data: Ying Zhao, Yong-You Wu, Gen Li, Hui-Ying Cheng, Meng Zhang, Feng Lai; writing and revision of the manuscript: Qiu Chen, Ya-Nan Zeng, Ke Zhang.

\section{Competing Interests}

The authors have declared that no competing interest exists. 


\section{References}

1. Ferlay J, Soerjomataram I, Dikshit R, et al. Cancer incidence and mortality worldwide: sources, methods and major patterns in GLOBOCAN 2012. INT J CANCER. 2015; 136(5): E359.

2. Melsens E, Verberckmoes B, Rosseel N, et al. The VEGFR Inhibitor Cediranib Improves the Efficacy of Fractionated Radiotherapy in a Colorectal Cancer Xenograft Model. EUR SURG RES. 2017; 58(3-4):95-108.

3. Holm T, Fletcher G. Preoperative radiotherapy combined with total mesorectal excision for resectable rectal cancer. Retour Au Numéro. 2002. 127(10):78

4. Mihandoost E, Shirazi A, Mahdavi SR, Aliasgharzadeh A. Canmelatonin help us in radiation oncology treatments? BioMed ResInt. 2014; 2014:12.

5. Reid PA, Wilson P, Li Y, Marcu LG, Bezak E. Current understanding of cancer stem cells: Review of their radiobiology and role in head and neck cancers. Head Neck. 2017 Sep;39(9):1920-1932.

6. Gomez-Casal R, Bhattacharya C, Ganesh N, et al. Non-small cell lung cancer cells survived ionizing radiation treatment display cancer stem cell and epithelial-mesenchymal transition phenotypes. MOL CANCER. 2013; 12(1):94.

7. Piao LS, Hur W, Kim TK, et al. CD133+ liver cancer stem cells modulate radioresistance in human hepatocellular carcinoma. Cancer Letters. 2011; 315(2):129-137.

8. Chiou SH, Kao CL, Chen YW, et al. Identification of CD133-Positive Radioresistant Cells in Atypical Teratoid/Rhabdoid Tumor. PLoS One. 2008; 3(5): e2090.

9. Bao $\mathrm{S}, \mathrm{Wu} \mathrm{Q}, \mathrm{Mclendon} \mathrm{R} \mathrm{E}$, et al. Glioma stem cells promote radioresistance by preferential activation of the DNA damage response. Nature. 2006; 444(7120):756-60.

10. Gao X, Mcdonald J T, Hlatky L, et al. Acute and fractionated irradiation differentially modulate glioma stem cell division kinetics. CANCER RES. 2013; 73(5):1481.

11. Du QH, Peng $\mathrm{C}$, Zhang H. Polydatin: a review of pharmacology and pharmacokinetics. PHARM BIOL. 2013; 51(11):1347-54.

12. Xu XX, Wang XY, Tan B, et al. Effects of polydatin on inflammatory response in MODS rats. World J Med Today. 2007; 8: 3-5

13. Shu SY, Wang XY, Ling ZY, et al. Effect of polydatin on phospholipase A2 in lung tissues in rats with endotoxicshock. Chinese Journal of Traumatology. 2004; 7(4):239-243.

14. Wang YX, Kang SH, Zhang OF, et al. The effect of polydatin on anticancer and cancer cell cycle in transplanted swelling mice. Zhe jiangJ Integr Trad Chin Western Med. 2003; 13: 287-289

15. Zhang $Y$, Zhuang Z, Meng Q, et al. Polydatin inhibits growth of lung cancer cells by inducing apoptosis and causing cell cycle arrest. ONCOL LETT. 2014; 7(1):295.

16. Huang ZS, Wang ZW, Liu MP, Zhong SQ, Li QM, Rong XL. Protective effects of polydatin against CCl4-induced injury to primarily cultured rat hepatocytes. World J Gastroenterol.1999; 5: 41-44

17. Neufert C, Becker C, Neurath MF. An inducible mouse model of colon carcinogenesis for the analysis of sporadic and inflammation-driven tumor progression. Nat Protoc. 2007; 2(8): 1998-2004

18. Carmon KS, Gong X, Lin Q, et al. R-spondins function as ligands of the orphan receptors LG R4 and LG R5 to regulate Wnt / beta-catenin signaling. Proc Natl Acad Sci U S A. 2011; 108 (28): 11452-11457.

19. Yui S, Nakamura T, Sato T, et al. Functional engraftment of colon epithelium expanded in vitro from a single adult Lgr5 + stem cell. Nat Med. 2012; 18(4): 618-623.

20. Barker N, van Es JH, Kuipers J, et al. Identification of stem cells in small intestine and colon by marker gene Lgr5. Nature.2007; 449(7165) : 1003-1007

21. Auclair BA, Benoit YD, Rivard N, Mishina Y, Perreault N. Bone morphogenetic protein signaling is essential for terminal differentiation of the intestinal secretory cell lineage. Gastroenterology. 2007;133: 887-896.

22. Kimura T, Nakano T. Regulation of Stem Cell Systems by PI3K/Akt Signaling. In: Regulatory Networks in Stem Cells. Berlin, Germany: Springer; 2009: Part IV: 309-318.

23. Fre S, Huyghe M, Mourikis P, Robine S, Louvard D, Artavanis-Tsakonas S. Notch signals control the fate of immature progenitor cells in the intestine. Nature. 2005;435: 964-968.

24. Nishimura $Y$, Nakagawa K, Takeda K, et al. Phase I/IItrial of sequential chemoradiotherapy using a novel hypoxic cell radiosensitizer, doranidazole( PR-350), in patients with locally advanced non-small-cell lung cancer( WJTOG-0002). Int J Radiat Oncol Biolphys.2007; 69( 3) : 786-792.

25. Belshaw Z, Constantio-Casas F, Brearley MJ, et al. COX-2 expression and outcome in canine nasal carcinomas treated with hypofractionated radiotherapy. Vet Comp Oncol. 2011; 9 (2):141-148.

26. Raftery L, Tepper JE, Goldberg RM, et al. A two-cohort phase I study of weekly oxaliplatin and gemcitabine, then oxaliplatin, gemcitabine, and erlotinib during radiotherapy for unresectable pancreatic carcinoma. Am J Clin Oncol.2013; 36(3): 250-253.

27. Shi HS, Gao X, Li D, et al. A systemic administration of liposomal curcumin inhibits radiation pneumonitis and sensitizes lung carcinoma to radiation. Int J Nanomedicine. 2012; (7): 2601-2611.

28. Matuschek C, Bölke E, Belka C, et al. Feasibility of 6-month maintenance cetuximab after adjuvant concurrent chemoradiation plus cetuximab in squamous cell carcinoma of the head and neck. Strahlenther Onkol.2013;189( 8) : 625-631.

29. Zhang $Y$, Zhuang Z, Meng Q, et al. Polydatin inhibits growth of lung cancer cells by inducing apoptosis and causing cell cycle arrest. ONCOL LETT.2014; 7(1):295.

30. De M S, Scognamiglio I, Lombardi A, et al. Polydatin, a natural precursor of resveratrol, induces cell cycle arrest and differentiation of human colorectal Caco-2 cell. J TRANSL MED. 2013; 11(1):264.

31. Clarke M F, Dick J E, Dirks P B, et al. Cancer stem cells--perspectives on current status and future directions: AACR Workshop on cancer stem cells. CANCER RES. 2006; 66(19):9339-9344.

32. Diehn M. Investigating Mechanisms of Cancer Stem Cell Radioresistance. INT J RADIAT ONCOL.2008; 72(1): S29-S29.

33. López J, Poitevin A, Mendoza-Martínez V, et al. Cancer-initiating cells derived from established cervical cell lines exhibit stem-cell markers and increased radioresistance. BMC Cancer. 2012; 12(1):48.

34. Ziskin JL, Dunlap D, Yaylaoglu M, Fodor IK, Forrest WF, Patel R, Ge N, Hutchins GG, Pine JK, Quirke P, Koeppen H, Jubb AM. In situ validation of an intestinal stem cell signature in colorectal cancer. Gut. 2012;25.

35. Kemper K, Prasetyanti PR, De Lau W, Rodermond H, Clevers H, Medema JP. Monoclonal antibodies against Lgr5 identify human colorectal cancer stem cells. Stem Cells. 2012;30(11) :2378-86.

36. Tian Y, Ma X, Lv C, Sheng X, Li X, Zhao R, Song Y, Andl T, Plikus MV, Sun J, Ren F, Shuai J, Lengner CJ, Cui W, Yu Z. Stress responsive miR-31 is a major modulator of mouse intestinal stem cells during regeneration and tumorigenesis. Elife. 2017 Sep 5;6. pii: e29538.

37. Cui S, Chang PY. Current understanding concerning intestinal stem cells. World J Gastroenterol. 2016; 21;22(31):7099-110 